\title{
Análise de fraturamentos para determinação de áreas instáveis na faixa de dutos Osvat/Osplan - São Sebastião, em São Paulo
}

\author{
Cristiane Alessandra de Moura ${ }^{1 *}$, Juércio Tavares de Mattos ${ }^{2}$,Jairo Roberto Jiménez-Rueda ${ }^{3}$
}

\begin{abstract}
Resumo O presente trabalho buscou caracterizar, na faixa de dutos Osvat/Osplan em São Sebastião, São Paulo, as feições geológicas que individualizam áreas com elevado grau de ruptilidade (fraturamento). Adotou-se, como sistemática de mapeamento, a análise de estruturas geológicas rúpteis (lineamentos estruturais e traços de juntas), por meio das técnicas de sensoriamento remoto orbital. Quando essas feições foram analisadas, pôde-se inferir sobre fatores como permeabilidade, infiltração e grau de cisalhamento da região, fatores esses que condicionam os processos erosivos e gravitacionais da área. Sobre o mapa de lineamentos estruturais, foram analisados os pontos de cruzamento de lineamentos de diferentes direções e foi feita a contagem da frequência desses pontos por unidade de área, possibilitando a modelagem estatística da distribuição espacial, gerando o mapa da densidade de cruzamentos de lineamentos estruturais, que permite determinar áreas com maior percolação de fluidos no maciço. Já no mapa de traços de juntas, realizou-se uma análise espacial para identificar as duas direções de maior frequência de juntas, de forma a estabelecer os máximos 1 e 2 e identificar as zonas de variação bruscas de direções dessas juntas. Nestas áreas onde ocorrem mudanças bruscas de direções de máximos de junta, ocorre intensa percolação de fluidos, responsável pela maior alterabilidade do complexo rocha/solo, facilitando a instalação de processos erosivos e gravitacionais, aumentando a instabilidade da área e, consequentemente, a vulnerabilidade da dutovia.
\end{abstract}

Palavras-chave: imagens de satélite; análise de fraturamento; meio físico e dutos.

\begin{abstract}
Analysis of fracturing to determine areas of instability in the strip of intervention of the Osvat/Osplan pipeline in São Sebastião, state of São Paulo. The present work aimed at characterizing geological features that identify areas with high ruptibility (fracturing) in the Osvat/Osplan pipeline in São Sebastião, São Paulo. The analysis of ruptile geological structures (lines of strikes and structural lineaments) through the use of orbital remote sensing was used as systematic mapping. The analysis of these features enables the inference of factors, such as permeability, infiltration and degree of shear in the region, factors which influence the processes of erosion and landslides in the area. On the map of structural lineaments, points of lineaments intersection from different directions were analyzed, followed by the counting of the frequency of these items per unit area, allowing the statistical modeling of spatial distribution, generating the map of density of structural lineament intersections, which allows determining areas with the highest percolation of fluid in the rock structure. However, on the map of lines of strikes, a space analysis was conducted to identify the two directions with higher frequency of lines of strikes in order to establish the maximums 1 and 2 and to identify the areas of abrupt changes of direction of these strike lines. In such areas where abrupt changes of directions of maximum lines of strikes occur, consequently there will be intense percolation of fluids, responsible for higher alterability of the rock/soil complex, facilitating the installation of erosion processes and landslides, increasing the area instability and consequently the vulnerability of the pipeline.
\end{abstract}

Keywords: satellite images; analysis of fracturing; physical environment and pipelines.

\section{INTRODUÇÃOO Obras de engenharia line-} ares, como rodovias, dutos e linhas de transmissão, são responsáveis pelo aumento dos processos erosivos e gravitacionais devido à mudança das características naturais do terreno. Essa situação torna imprescindível a execução de estudos do meio físico, os quais busquem suprir a demanda por mapeamentos que priorizem obras deste tipo. Esses estudos devem caracterizar os elementos ambientais existentes nas áreas interferidas por essas dutovias e, a partir disto, determinar quais trechos nestas faixas podem ser impactados por processos de instabilidade ambiental.

A faixa de dutos escolhida para o mapeamento foi a Osvat/Osplan, localizada nos municípios de São Sebastião e Caraguatatuba no litoral norte paulista. Essa faixa está em operação desde a década de 1970, portanto, já tem mais de 30 anos de funcionamento. Os dutos existentes nessa faixa transportam boa parte

${ }^{1}$ Instituto de Geociências e Ciências Exatas, Programa de Pós-graduação em Geociências e Meio Ambiente Campus, Universidade Estadual Paulista - Unesp, Rio Claro (SP), Brasil. E-mail: cristimoura@hotmail.com

${ }^{2}$ Faculdade de Engenharia da Universidade Estadual Paulista - Unesp, Campus de Guaratinguetá, Guaratinguetá (SP), Brasil. E-mail: juercio@feg.unesp.br

${ }^{3}$ Instituto de Geociências e Ciências Exatas, Universidade Estadual Paulista - Unesp, Campus Rio Claro, Rio Claro (SP), Brasil.

E-mail: jairorjr@rc.unesp.br

*Autor correspondente 
dos hidrocarbonetos que abastecem as refinarias do Planalto Paulista.

Neste trabalho, foram interpretadas as principais deformações tectônicas da área de estudo e suas respectivas estruturas: lineamentos estruturais, sistemas de juntas, zonas de variação de traços de juntas (máximos 1 e 2), com o objetivo de determinar na faixa de dutos Osvat/Osplan as áreas com maior propensão a instabilizações por processos erosivos e gravitacionais.

\section{CARACTERIZAÇÃO DA ÁREA DE ESTUDO}

A área de estudo (Fig. 1) compreende as Folhas Topográficas Pico do Papagaio, Caraguatatuba, Maresias e São Sebastião e está localizada entre as coordenadas $23^{\circ} 30^{\prime} / 45^{\circ} 45^{\prime}$ e $24^{\circ} 00^{\prime} / 45^{\circ} 15^{\prime}$ no estado de São Paulo, dentro do Planalto Atlântico e da Província Costeira.

As principais vias de acesso a área de estudo são as Rodovia Rio-Santos (BR 101/SP 55) e dos Tamoios (SP 099). Há também como alternativa de acesso ao duto Osvat/Osplan a estrada não pavimentada, que liga Salesópolis à Caraguatatuba.

O trecho da faixa do polidutos Osvat/Osplan mapeado possui aproximadamente $39 \mathrm{~km}$ de extensão. Essa faixa é considerada de grande importância econômica, pois transporta o maior volume de hidrocarbonetos do Brasil, estendendo-se do Terminal de São Sebastião - considerado o maior da América Latina - às refinarias do Planalto Atlântico Paulista.
Tal área de estudo faz parte da região geomorfológica denominada Província Costeira, dividida por Almeida (1964) em Serranias Costeiras e Zona da Baixada Litorânea. Na área de estudo, as planícies costeiras possuem ocorrência restrita e estão distribuídas por um litoral bastante recortado, no qual são frequentes as enseadas e as praias. A costa é abruptamente interceptada pela borda oriental do Planalto Atlântico, com ocorrência de pontões rochosos perpendiculares à direção geral desta estrutura, os quais favorecem a formação de baías.

O forte controle estrutural na área e os processos de sedimentação quaternária são considerados os fatores responsáveis pelo desenvolvimento da morfologia da região. Segundo Cruz (1974), a direção da Serra do Mar na área de estudo comanda a linha de costa e depende da maior ou menor aproximação da serra com o mar. Quando a direção da costa é NE$\mathrm{SW}$, as linhas de costa caracterizam-se como altas e maciças, com costões e praias de tombo. Quando a direção da linha de costa é N-S, há reentrâncias, enseadas e praias mais calmas.

A área de estudo encontra-se inserida no Complexo Costeiro, genericamente representado por formações geológicas do Pré-Cambriano e Cenozoico, que se estende ao longo da costa Sudeste do Brasil. A geologia desta área é marcada por redes de zonas de cisalhamento transcorrentes, que estão associadas à evolução do Cinturão de Dobramento Orogênico

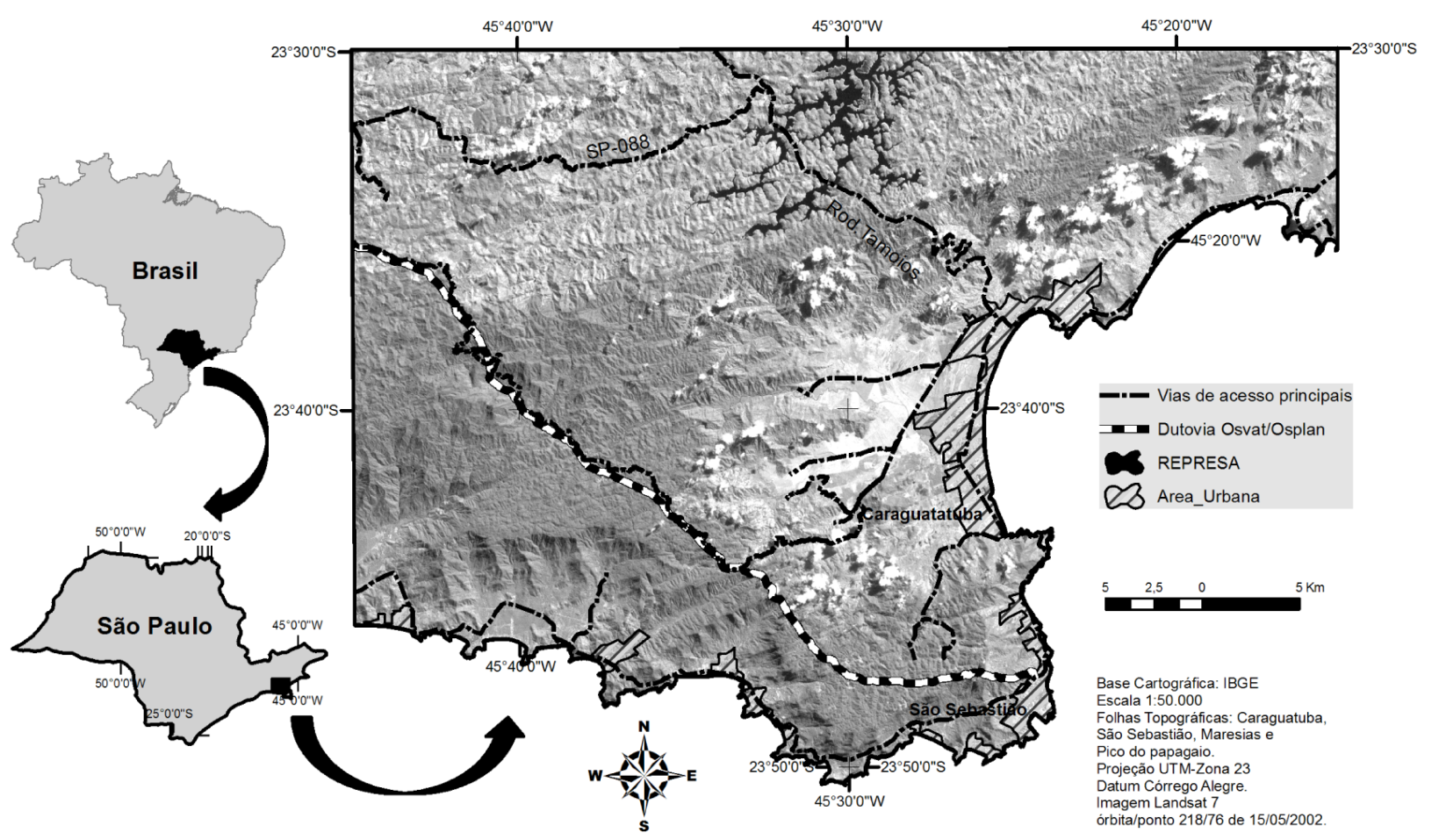

Figura 1 - Localização da área de estudo e da faixa de dutos Osvat/Osplan. 
Ribeira, ligado a Orogênese Brasiliana Pan-Africana (Maffra 2000). A área de estudo localiza-se a Sudeste do Cinturão Ribeira, é transectada de oeste para leste pelas seguintes estruturas: Zona de Cisalhamento Bairro do Alto, Zona de Cisalhamento Camburu e Sistema de Cavalgamento São Sebastião (Fig. 2).

O cinturão de cisalhamento transcorrente Paraíba do Sul, de orientação NE-SW, sofreu uma transpressão dextral, enquanto que a porção norte-sul apresenta um sistema de cavalgamento essencialmente frontal. Este quadro deu origem a uma condição estrutural complexa, gerando domínios de deformação tangencial, com foliação com mergulhos moderados e lineações suaves e indicações cinemáticas de cavalgamentos para NW e domínio de deformação transcorrente. As estruturas regionais apresentam um trend $\mathrm{NE}$ e correspondem a fatias de cisalhamento dúcteis, sub-horizontais para o Noroeste, seguidas
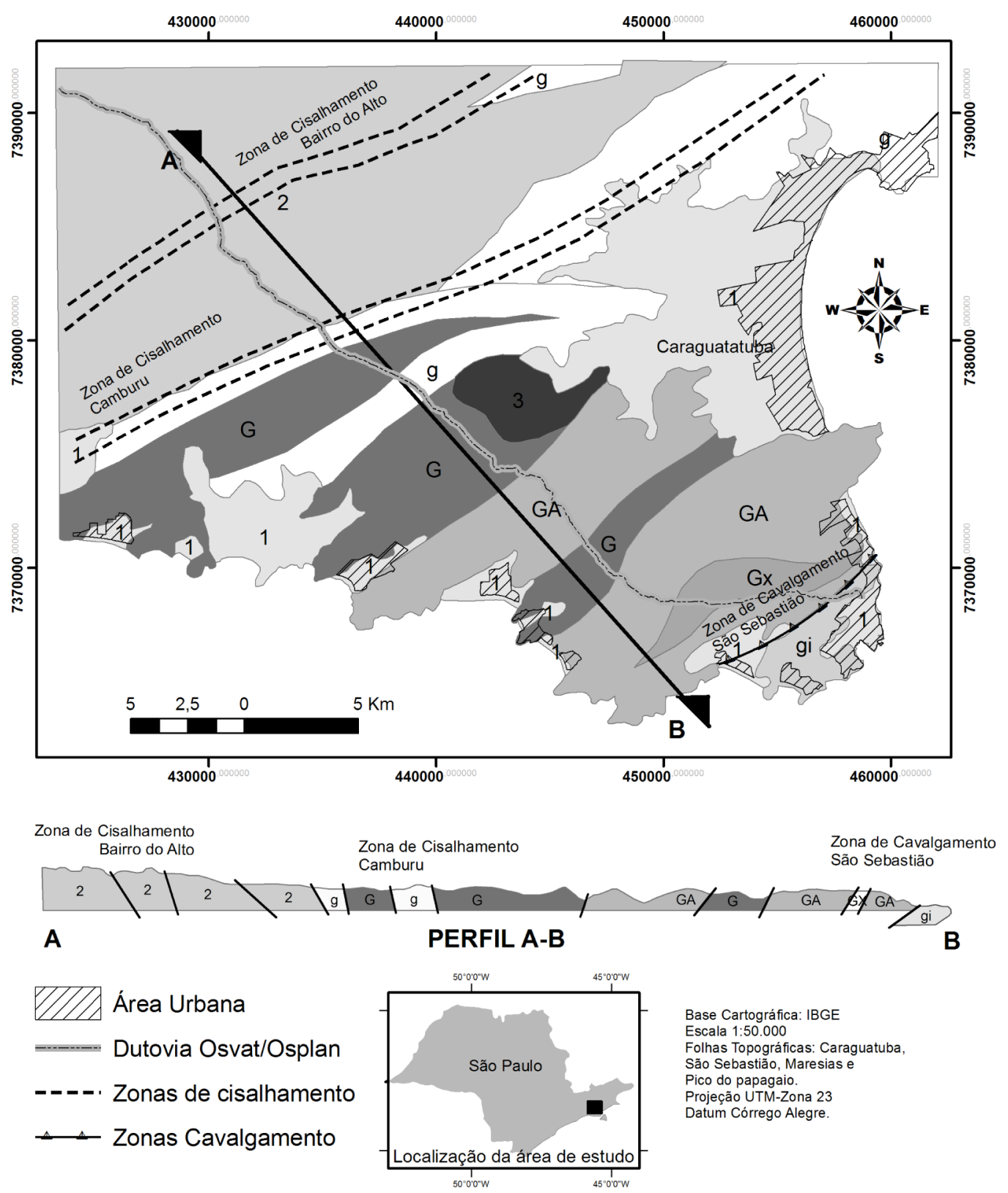

Base Cartográfica: IBGE Escala 1:50.000 Folhas Topográficas: Caraguatuba São Sebastião, Maresias e Pico do papagaio. Projeção UTM-Zona 23 Datum Córrego Alegre.

1: sedimentos quaternários; 2: granitoides gnaissicos (Granito Pico do Papagaio); 3: metagabros, metadioritos e enderbitos parcialmente migmatizados (Complexo Bairro do Marisco); g: granitoides gnaissicos equigranulares, oftálmicos e nebulíticos; subordinadamente gnaisses, xisto e anfibolitos; gi-leucogranito gnaissico com granada; G: biotita, gnaisses e migmatito frequentemente com granada e silimanita; subordinadamente anfibolitos, kinzigitos, corpos nebulíticos e rochas cálcio-silicáticas; GA: biotita gnaisses e migmatitos com frequente intercalações de anfibolitos; GX: biotita gnaisses e xistos com intercalações de quartzitos.

Figura 2 - Mapa geológico e perfil esquemático do planalto de Juqueriquerê e adjacências. Modificado de Campanha, Ens \& Ponçano (1994). 
por uma pilha de cavalgamentos para a mesma direção, que são, por sua vez, superpostos por cinturões de cisalhamentos transcorrentes. São comuns estruturas do tipo em flor (regionais) e extrusão lateral (Ebert \& Hasui apud Maffra 2000).

Essa situação tectônica, caracterizada por blocos falhados e desnivelados, permitiu a formação da Serra do Mar, na qual os processos erosivos passaram a atuar intensamente a partir do Jurássico Superior, com a Reativação Wealdeniana (Garda 1995).

Na região de São Lourenço foram reconhecidas, na porção NW, rochas granitoides gnaissificadas (Granito Pico do Papagaio) e, ao Sul, separado pela zona de cisalhamento Camburu, um conjunto de rochas predominantemente paraderivadas, migmatizadas e rochas metabásicas (Campanha \& Ens 1996).

A falha do Camburu está inserida numa zona de cisalhamento pré-cambriana e foi reativada durante o Juro Cretáceo, com a intrusão de espessos diques de rochas básicas e o abatimento do planalto do Juqueriquerê no Terciário, dando-se origem a intercalações milimétricas a métricas de brechas cataclásticas silicificadas (Campanha \& Ens 1996).

Conforme Campanha \& Ens (1996, p. 44): “a Falha do Camburu constitui uma faixa de dezenas a centenas de metros de espessura de rochas miloníticas, ultramiloníticas, blastomiloníticas e protomiloníticas, predominantemente quartzo feldspáticas".

As rochas ígneas existentes na área incluem três tipos distintos: granulíticas, graníticas de composição e texturas variadas e metabásicas. As rochas granulíticas, principalmente as charnockíticas, têm sido exploradas com finalidades ornamentais de revestimento, sendo conhecidas no mercado como "Granito Verde Ubatuba" (Jorge 2000).

De acordo com Almeida (1963) apud Garda (1995), a reativação Wealdeniana teve início no Jurássico Superior, período em que ocorreram dois eventos magmáticos em fases distintas, o primeiro, de caráter básico e intermediário, é representado por diques e sills, e o segundo, por stocks ou chaminés e diques de rochas alcalinas.

\section{MATERIAIS E MÉTODOS}

Materiais Os softwares utilizados foram Arcgis 9, da ESRI, e Spring 5, do Instituto Nacional de Pesquisas Espaciais (INPE), para a vetorização de dados, manipulação das imagens de satélite (contraste) e elaboração de banco de dados geográficos.
Foram utilizadas as imagens Landsat 7 ETM+ (bandas 1, 2, 3, 4, 5, 6, 7 e pancromática) órbita/ponto 218/76, de 15 de maio de 2002, com resolução espacial de $30 \mathrm{~m}$ (bandas 1 a 7) e de $15 \mathrm{~m}$ (pancromática). Essas imagens foram transformadas do formato Tiff para formato Grib no módulo Impima do programa Spring. O registro ou georreferenciamento das imagens foi executado no programa Spring, utilizando-se a base cartográfica vetorial do projeto Concepção, Desenvolvimento, Implementação, Aplicação e Elaboração de Cartas SÃO: Litoral Paulista e da Base de dados do Instituto Brasileiro de Geografia e Estatística (IBGE). As imagens utilizadas foram realçadas em operação linear para melhor distribuição dos níveis de cinza e, consequentemente, melhor interpretação.

Também foram utilizadas as cartas topográficas escala 1:50.000 do IBGE: Pico do Papagaio SF-23-YD-V-2, Caraguatatuba SF -23-Y-D-VI-1, Maresias SF23-Y-D-V-4 e São Sebastião SF -23-Y-D-VI-3, editadas em 1974, 1976, 1973 e 1969, respectivamente.

\section{Métodos}

Carta de lineamentos estruturais e traços de juntas Conforme Loczy e Ladeira (1976), a tectônica investiga a morfologia e a associação das estruturas de tipos similares, classificando-as ou agrupando-as em zonas e regiões, procurando obter uma visão integrada das estruturas maiores e suas relações espaciais entre si.

$\mathrm{Na}$ análise do fraturamento, efetuou-se o estudo das estruturas que condicionam a drenagem e o relevo, sendo essas as feições lineares de drenagem (traços de juntas), alinhamentos de drenagem (lineamentos estruturais) e suas relações espaciais, permitindo estabelecer e classificar zonas com diferentes graus de tectonismo, cisalhamento e ruptilidade.

Loczy e Ladeira (1976) definem juntas ou diacláses como planos ou superfícies de fraturas, que dividem as rochas e ao longo dos quais não ocorreu deslocamento das paredes rochosas paralelamente aos planos de fratura, ou se o deslocamento ocorreu foi mínimo e não visível.

Os lineamentos estruturais são definidos por O’Leary et al. (1976) como uma feição linear, simples ou composta, contínua ou descontínua da superfície terrestre, cujas partes estão alinhadas em um arranjo retilíneo ou suavemente curvo, este arranjo difere substancialmente dos padrões de feições que lhe são adjacentes. 
O procedimento utilizado neste trabalho consistiu em explorar os atributos espaciais das imagens de satélite, utilizando-se uma avaliação textural das mesmas, análise de feições lineares de drenagem (traços de juntas), alinhamentos de drenagem e tonais (lineamentos estruturais - falhamentos). Os lineamentos estruturais são feições que representam descontinuidades penetrativas na crosta terrestre e que podem ser interpretados como falhamentos quando possuem movimentos relativos aparentes (falhas normais, inversas, reversas, transcorrentes e/ou direcionais) ou como discordâncias formacionais e/ou deformacionais. Na natureza essas estruturas, manifestam-se na superfície como traços contínuos ou descontínuos, retilíneos ou curvilíneos e, também, sinuosos, dependendo do tipo de estrutura que eles representam. Uma característica desses traços é sua forte estruturação (Franzoni 2000).

Após a extração dos fraturamentos (juntas e lineamentos estruturais), foram obtidas cartas derivadas tanto dos lineamentos estruturais como dos traços de juntas, como pode ser observado na Fig. 3.

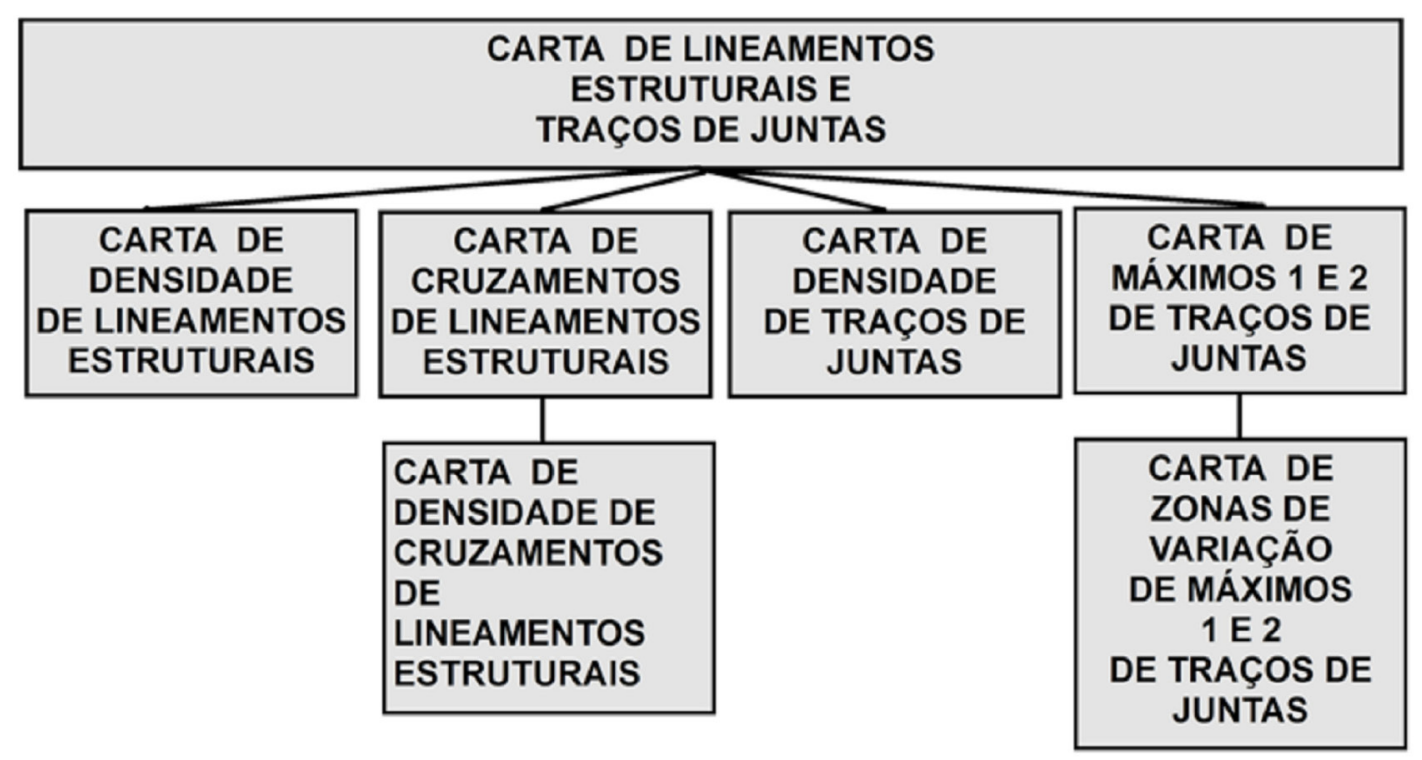

Figura 3 - Cartas derivadas dos lineamentos estruturais e dos traços de juntas.

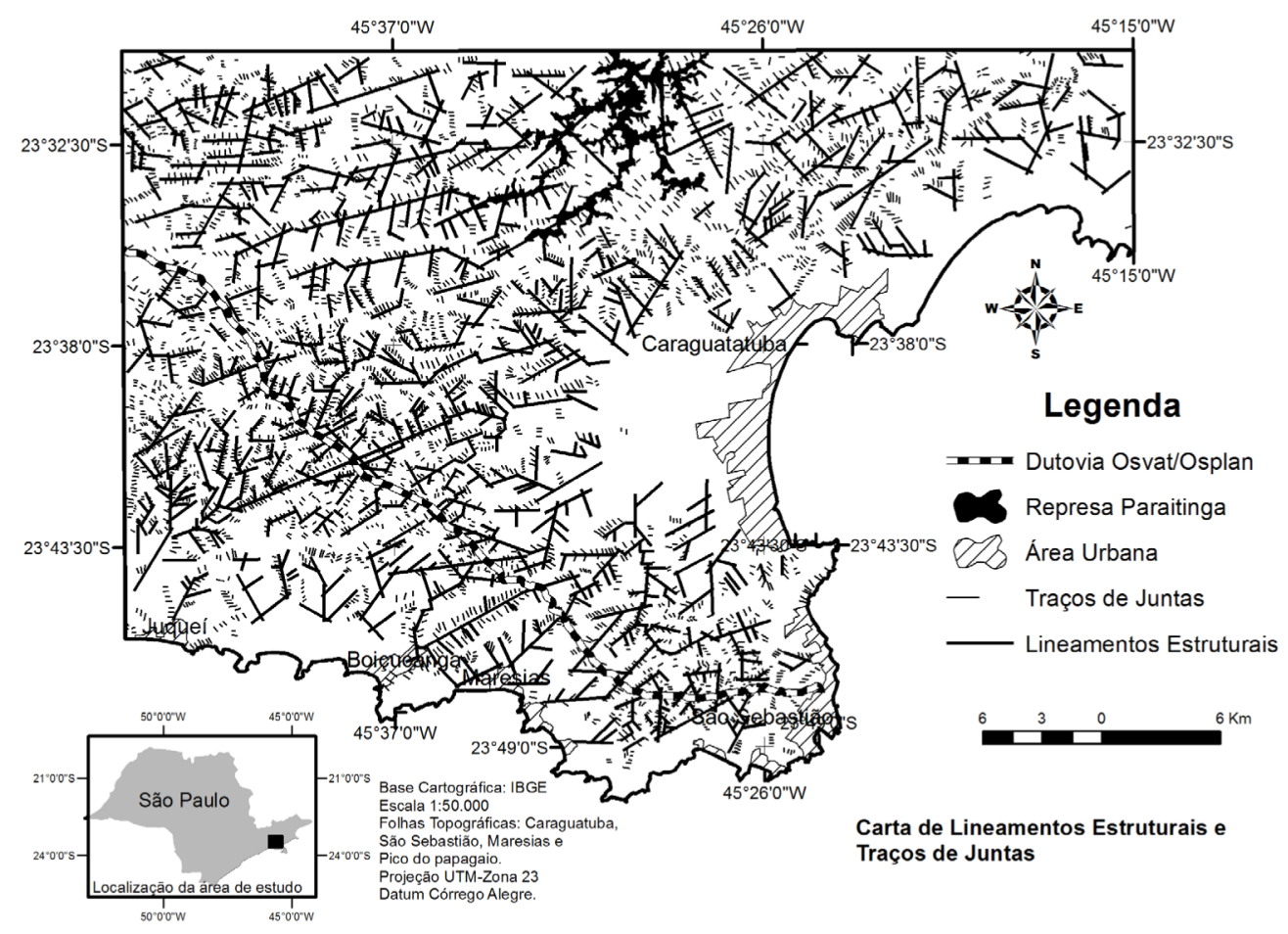

Figura 4 - Representação da carta de lineamentos estruturais e traços de juntas. 

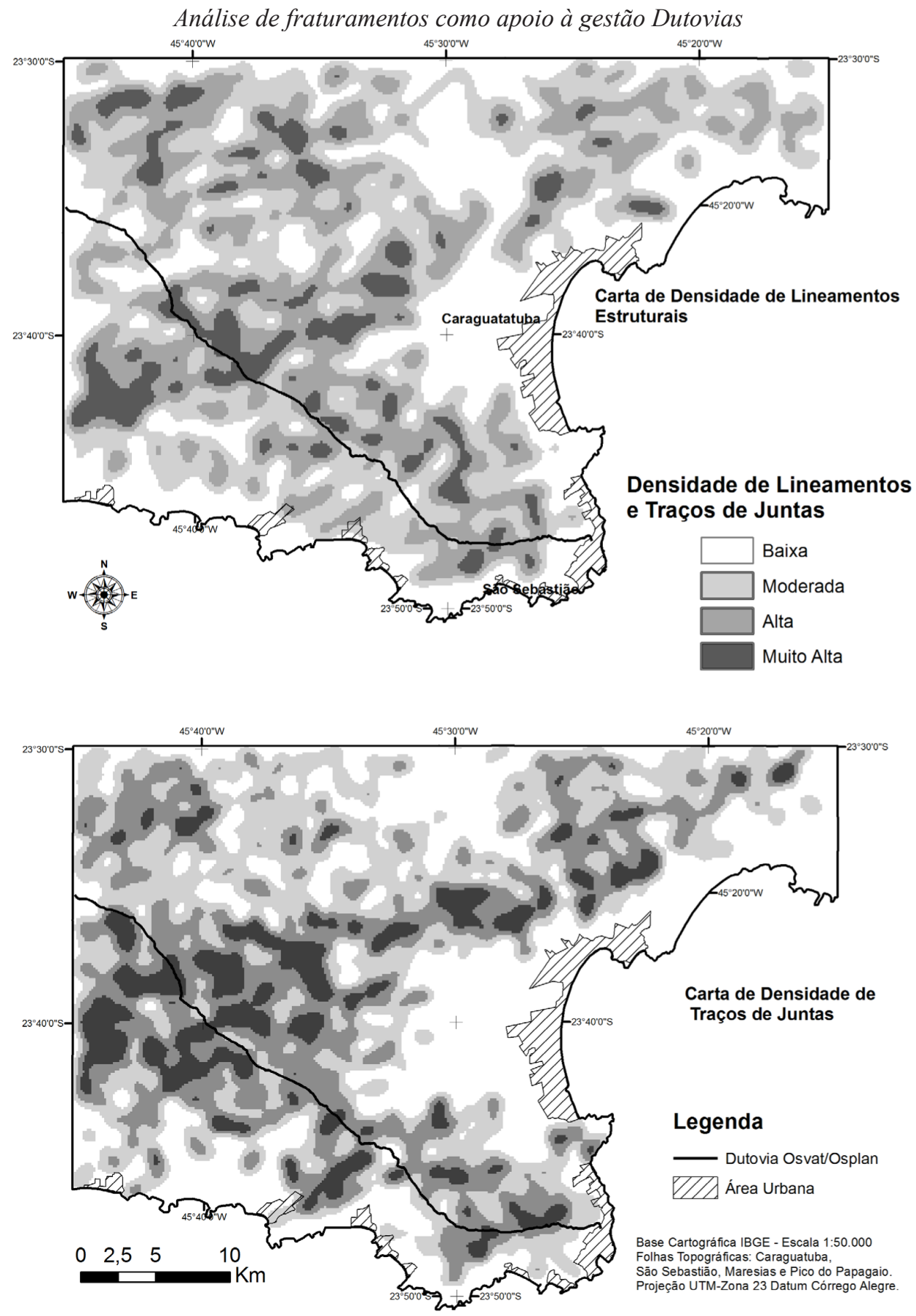

Figura 5 - Representações das cartas de densidade de lineamentos estruturais e traços de juntas.

Cartas de densidades de lineamentos estruturais e de traços de juntas As cartas de densidade de lineamentos estruturais e traços de juntas são derivadas da carta de fraturamento. Estas foram elaboradas utilizando o estimador por Kernel no programa Arcgis 9.0. Foram estabelecidos os parâmetros de entrada para a geração da carta em célula de saída 100 por $100 \mathrm{~m}$ e raio de busca de 1.500 .

Cartas de máximos 1 e 2 de traços de juntas e de zonas de variação de máximos 1 e $2 \quad$ A carta das zonas de variação de máximos 1 e 2 (as duas direções de maior frequência) é derivada da carta de traços de juntas. A carta de zonas de variação de máximos $1 \mathrm{e}$
2 determina as zonas mais fraturadas, portanto, mais instáveis.

Para a confecção dessa carta, fixou-se a escala em 1:50.000, no programa ArcGIS 9.0, após isso, moveu-se a carta e determinou-se para quadrantes de $25 \mathrm{~km}^{2}$ as duas direções preferenciais dos traços de juntas. O produto desta sequência caracteriza-se como carta de máximos 1 e 2. Esta carta originará a de Zonas de Variação de Máximos 1 e 2.

A filtragem dos traços das zonas de juntas em máximos 1 e 2 serve para verificar áreas em que o comportamento das direções principais varia, caracterizando-se regiões de variação de direção de máximos 1 e 2 (Crisóstomo Neto 2003). 
Cartas de cruzamentos de lineamentos estruturais e de densidade de cruzamentos de lineamentos estruturais Nas cartas de densidade de cruzamentos e lineamentos, foram utilizados os mesmos parâmetros das cartas de densidade de lineamentos estruturais e traços de juntas, ou seja, célula de saída 100 por $100 \mathrm{~m}$ e raio de busca de $1.500 \mathrm{~m}$.

\section{RESULTADOS E DISCUSSÃo A estrutura} geológica é um fator condicionante dos movimentos de massa e processos erosivos. A análise dos padrões de fraturas permite determinar planos de descontinuidades, que são locais onde ocorre intensa infiltração e circulação das águas e, portanto, são propícios a uma intensa intemperização das rochas. A velocidade do intemperismo químico depende tanto do sistema de juntas como da natureza das rochas, ou seja, o intemperismo é mais rápido e profundo onde o sistema de juntas é mais concentrado e/ou a rocha é menos resistente.

Os lineamentos mais proeminentes na área correspondem à Zona de Cisalhamento Camburu, que se trata de um lineamento bem definido com orientação NE, formando um baixo topográfico (vale) no planalto entre o granito Pico do Papagaio e o Augen Gnaissico Juqueí e à zona de cisalhamento Bairro do Alto (Maffra 2000).

$\mathrm{Na}$ carta de lineamentos estruturais e traços de junta (Fig. 4), a quantidade de lineamentos estruturais obtidos foi de 806 com comprimentos variando de 501 a $15.000 \mathrm{~m}$, a média de comprimentos desses lineamentos é de 1.615. Quanto aos traços de juntas, foram obtidos 4.010 , com o comprimento entre 65 a $500 \mathrm{~m}$ e uma média de $256 \mathrm{~m}$. A área de estudo, por apresentar quase em sua totalidade rochas do embasamento cristalino, é extremamente fraturada com alinhamentos de relevo e drenagem com extensões quilométricas.
Na carta de densidade de lineamentos estruturais e traços de juntas (Fig. 5), pôde-se observar a concentração dos traços de juntas bem como dos lineamentos estruturais na porção NW da área de estudo. Isso é devido à existência das zonas de cisalhamentos Camburu e Bairro do Alto, que condicionam fortemente o relevo e a drenagem da região. Na zona de cisalhamento Camburu, ocorre o interflúvio das bacias do planalto Paulistano, de Juqueriquerê e do Paraitinga e Paraibuna.

Nessa área de intenso fraturamento são favorecidos os processos naturais de alteração e erosão linear ou de fluxo concentrado (ranhura, sulco, vala e ravina), quando esta é submetida a intervenções humanas como cortes, escavações e aterros para instalação de obras de Engenharia. Essas intervenções podem provocar sobrepeso e levar ao desencadeamento de processos erosivos lineares, escorregamentos planares ou em cunha, bem como queda de blocos.

Segundo Peter et al. (1986), é recomendável o uso das cartas de densidade dos traços de junta e lineamentos estruturais, bem como da análise de frequência de direção, por meio do diagrama de rosetas, com o objetivo de determinar as áreas intensamente fraturadas.

No diagrama de rosetas (Fig. 6), observou-se que as direções preferenciais dos lineamentos estruturais são N20-50W e, secundariamente, N10W e N50-80E. Quanto aos traços de junta, a direção preferencial consiste em N30-40W e a secundária, EW.

A faixa de dutos Osvat/Osplan atravessa a área de estudo acompanhando a direção preferencial N20-50W dos lineamentos estruturais e N30$40 \mathrm{~W}$ dos traços de juntas, o que acarreta maior estabilidade à obra. No entanto, o duto corta perpendicularmente a direção secundária N50-80E dos lineamentos estruturais e EW dos traços de juntas, o que gera maior preocupação com estas áreas, as quais caracterizam-se como mais suscetíveis a processos erosivos concentrados e queda de

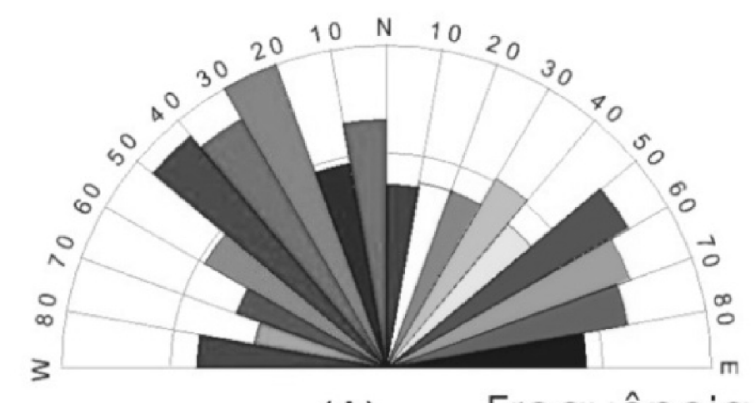

(A) Frequência Absoluta

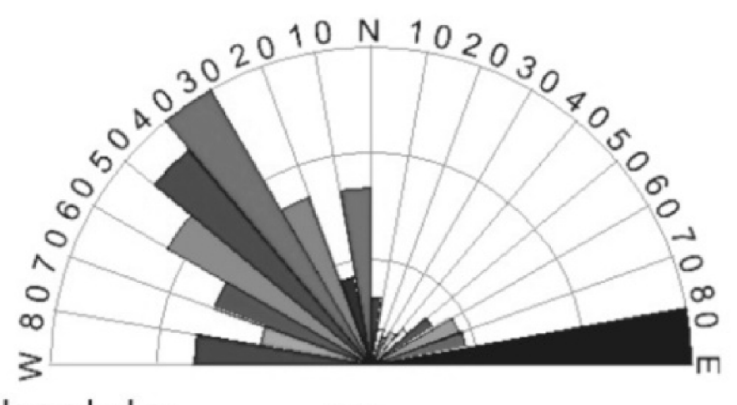

(B)

Figura 6-Diagramas de rosetas para os lineamentos estruturais (A) e traços de juntas (B). 


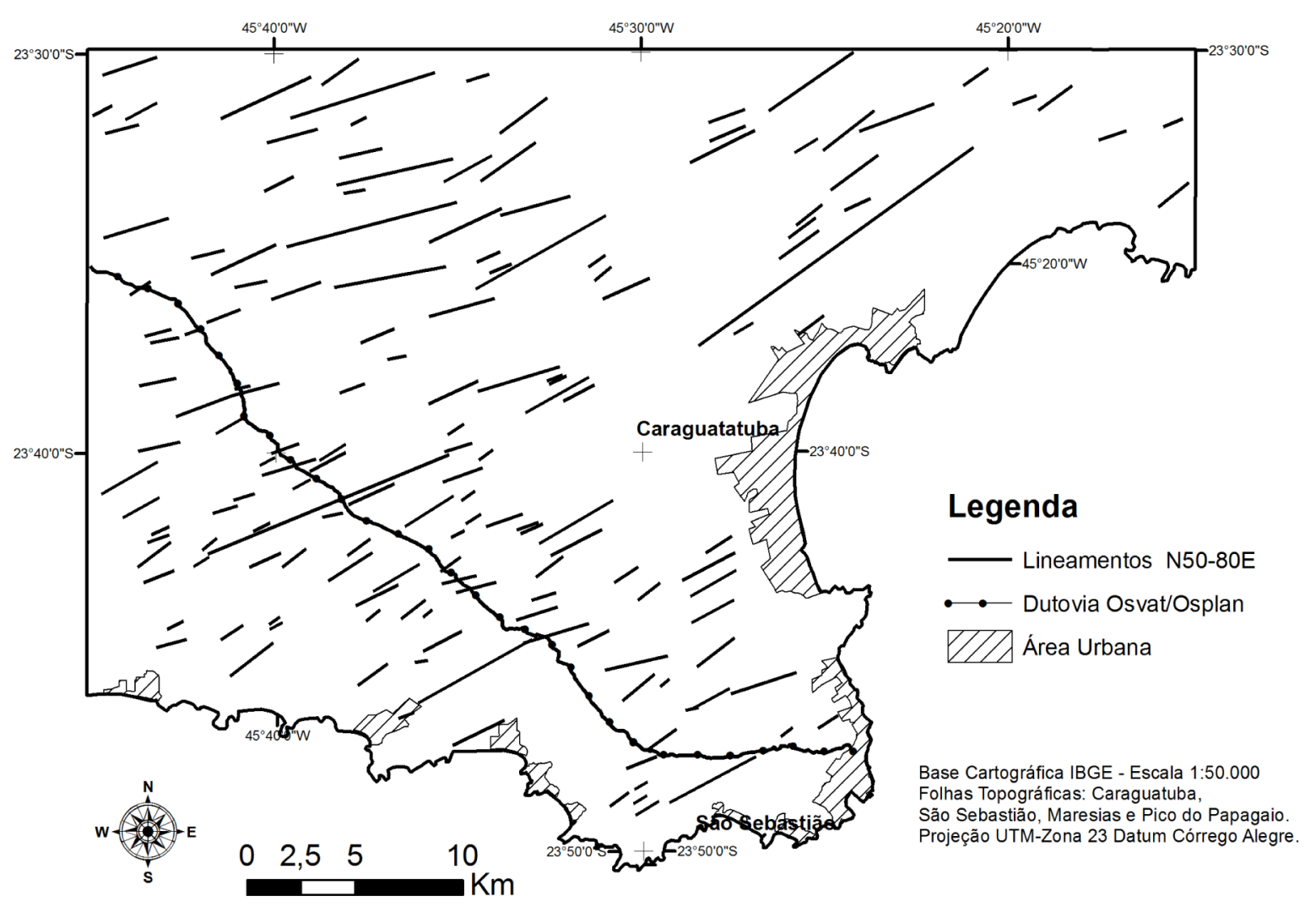

Figura 7 - Representação dos lineamentos estruturais secundários N50-80E na área de estudo.

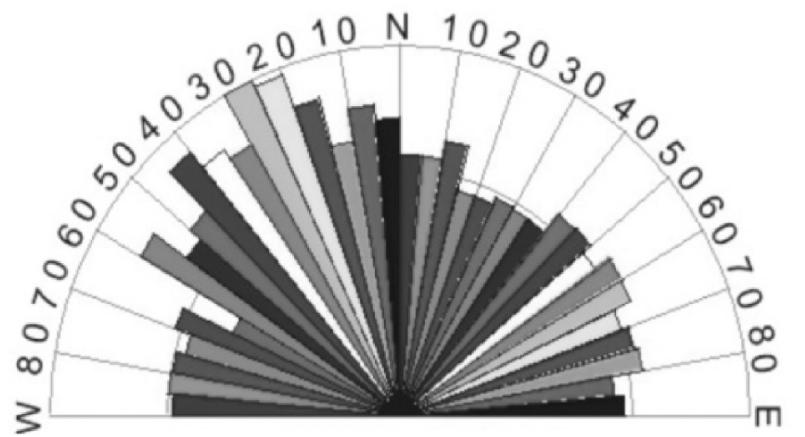

Frequência Absoluta

Figura 8 - Diagrama de rosetas dos elementos lineares da drenagem da área de estudo.

blocos, os quais são condicionados pelas direções dos fraturamentos.

A Fig. 7 mostra os lineamentos estruturais filtrados na análise de lineamentos do programa Sistema de Processamento de Informações Geográficas (SPRING), segundo suas direções para o intervalo N50-80E, na faixa de duto Osvat/Osplan.

A predominância das direções de lineamentos leva a crer que estas estão presentes em toda a área de estudo, ou seja, a instalação de obras lineares que cruzem perpendicularmente essas direções estruturais frequentes condiciona maior atenção nesses trechos específicos, pois tendem a apresentar processos erosivos e gravitacionais. Ao observar-se a Fig. 7 , nota-se a existência dessas estruturas em toda a faixa de dutos, com concentração próxima à região da zona de cisalhamento Camburu. Nessa área, um maior detalhamento é imprescindível devido a sua notável complexidade estrutural.

A orientação dos lineamentos de relevo e traços de juntas preferencialmente a NW ocorre na área de estudo devido à orientação NE-SW do Cinturão de Cisalhamento Transcorrente Paraíba do Sul.

A drenagem da área de estudo possui distribuição isotrópica, conforme o diagrama de rosetas (Fig. 8), apenas a direção N20-30W se destaca das demais. Comparando-se o resultado obtido com o dos traços de juntas e lineamentos de relevo, percebe-se o forte condicionamento da drenagem por estas estruturas.

A carta de zonas de variação de máximos $1 \mathrm{e}$ 2 foi obtida mediante a análise da carta de máximos 1 e 2 dos traços de juntas (Fig. 9). Conforme Mattos et al. (2002), a análise dos traços de junta em máximos 1 e 2 tem como objetivo determinar o processo de deformação regional e onde estes mudam bruscamente de direção, determinando as zonas nas quais existe uma variação no regime de campo de tensão 

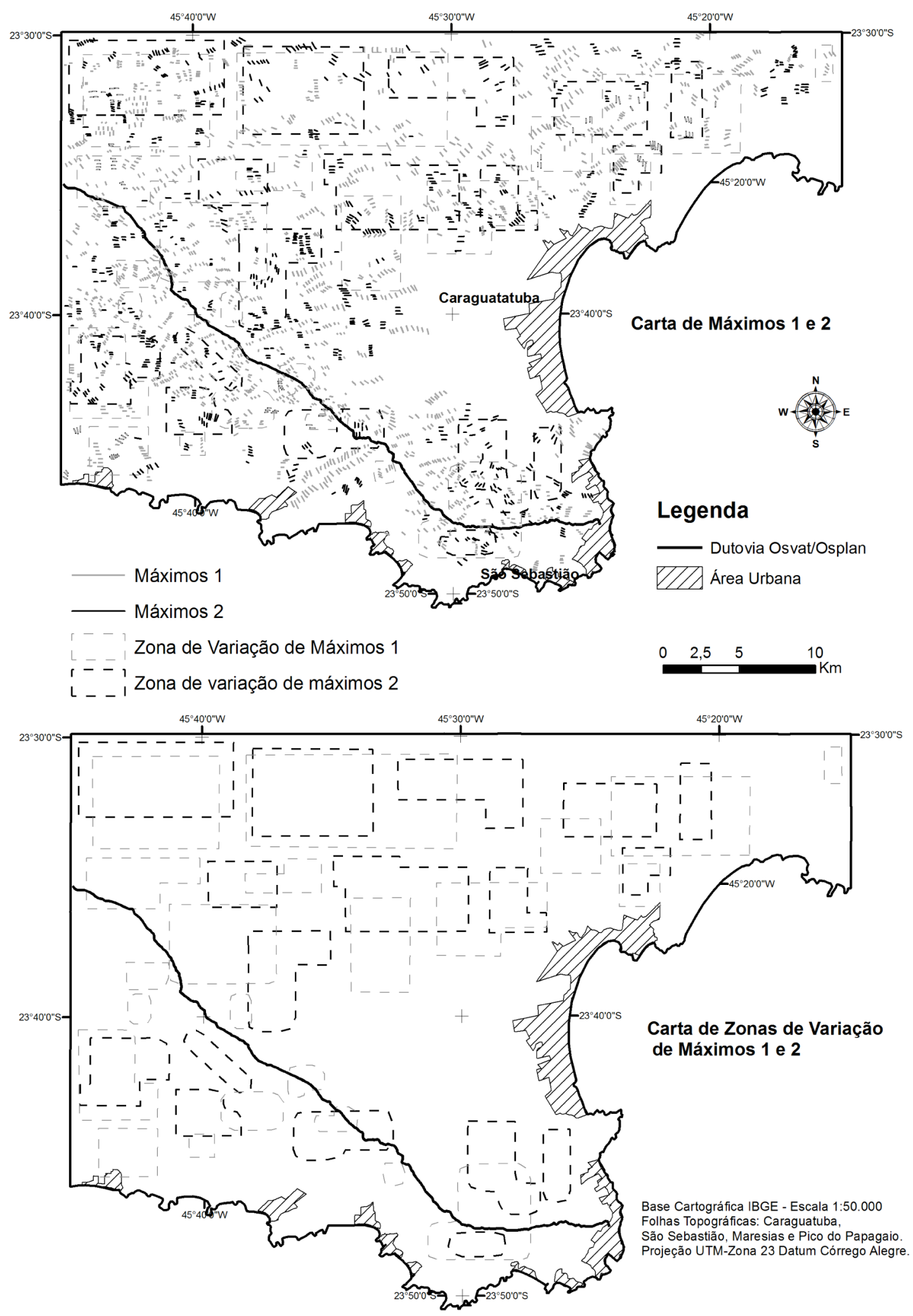

Figura 9 - Representação das cartas de máximos 1 e 2 (A) e das zonas de variação de máximos 1 e 2 (B).

da deformação, determinando áreas de maior fraturamento, ou seja, suscetibilidade à erosão.

As áreas mais fraturadas são aquelas em que há variação dos máximos 1 e 2, concomitantemente, seguidas daquelas em que há variação somente do máximo 1 e, finalmente, variação somente no máximo
2. As zonas de variação dos máximos de fraturamentos indicam zonas tectonicamente muito ativas. Estas são áreas fraturadas em várias direções, caracterizando materiais muito alterados, ou seja, muito decompostos, os quais podem ser considerados como muito suscetíveis a escorregamentos. 
$\mathrm{Na}$ área de estudo, mais especificamente no trecho da dutovia próxima à zona de escarpas festonadas voltadas para o município de São Sebastião, ocorre uma zona de variação dos máximos 1 e 2 . Assim sendo, esta se configura numa área de grande instabilidade ambiental com prováveis processos erosivos e gravitacionais, na qual localiza-se o sistema de cavalgamento São Sebastião. Outras zonas de variação de máximos ocorrem na região NW da área de estudo na faixa de cisalhamento transcorrente Camburu.

A carta da densidade de cruzamentos de lineamentos estruturais (Fig. 10) foi obtida da carta de cruzamentos de lineamentos estruturais. A carta de densidade de cruzamentos permite realizar a
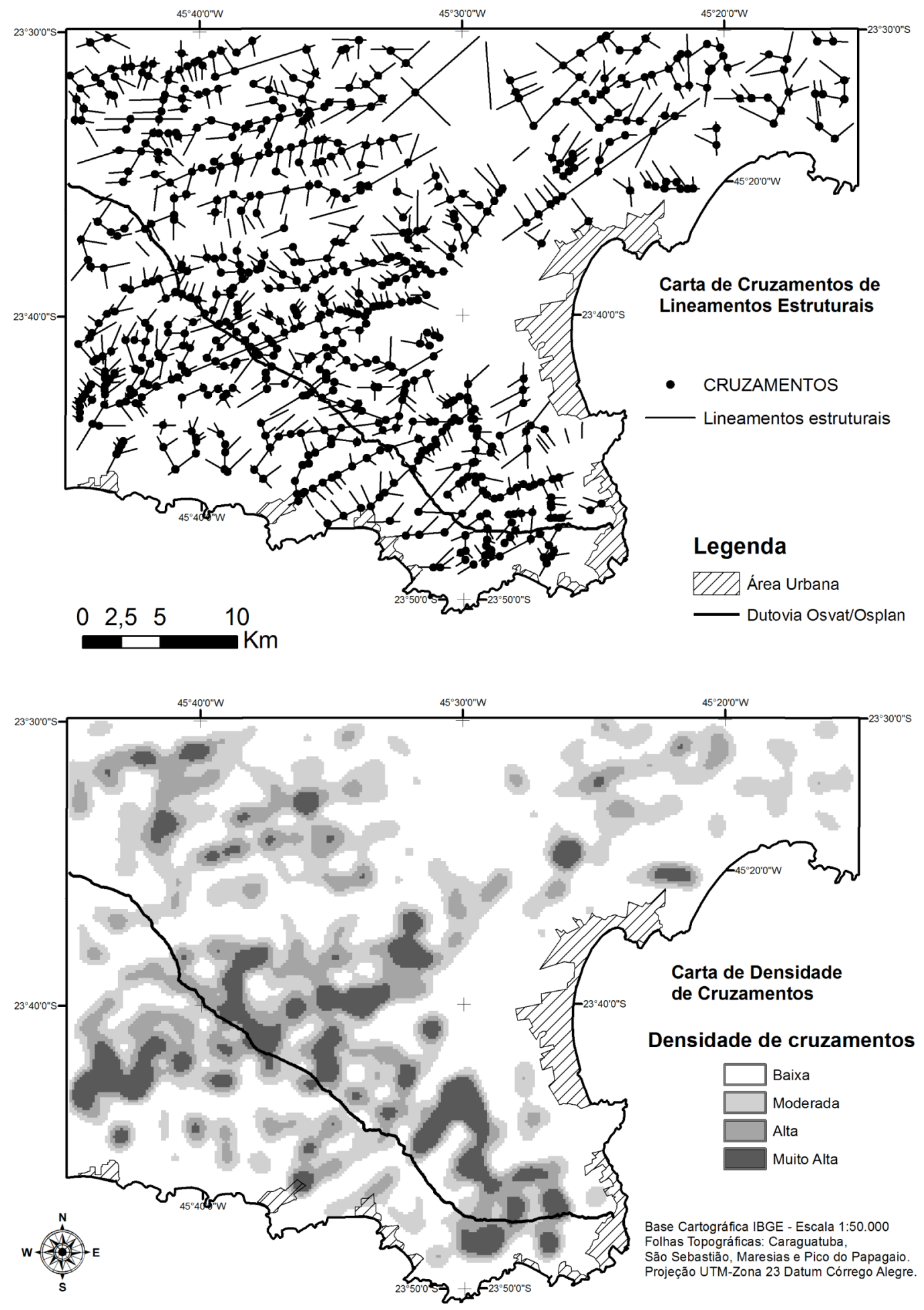

Figura 10 - Representação da carta cruzamentos de lineamentos e densidade de cruzamentos. 
avaliação em contexto regional das zonas de intenso cruzamento de fraturamentos.

Na Fig. 10 pode-se observar um eixo principal da intensidade de ocorrência de lineamentos e cruzamentos, que se estende da porção leste até a norte da área de estudo, com direção SW-NE representativa da Zona de Cisalhamento Camburu. Na porção NW da área de estudo, ocorre uma concentração de cruzamentos na região da zona de cisalhamento Bairro do Alto.

\section{CONCLUSÕES E RECOMENDAÇÕES A}

análise do fraturamento permitiu determinar as áreas em que a dutovia Osvat/Osplan pode estar mais suscetível a processos de instabilização, estas áreas estão próximas à zona de cisalhamento Camburu.

A área de estudo por se encontrar totalmente inserida no embasamento cristalino em trecho do cinturão de cisalhamento transcorrente Paraíba do Sul possui grande complexidade estrutural. Essas características garantem maior preocupação com instabilidades, como escorregamentos e processos erosivos. De acordo com esta afirmativa, obras de engenharia instaladas nesse ambiente - como no caso a dutovia Osvat/Osplan — devem receber atenção redobrada, por meio de monitoramentos constantes para evitar acidentes que causem impactos ambientais e socioeconômicos.

As obras lineares possuem especificidades quanto a sua escala de interferência, - muitas vezes continentais - portanto, necessitam de estratégias que viabilizem tecnicamente e financeiramente esses mapeamentos. O uso de tecnologias de sensoriamento remoto na análise dos padrões de fraturas e de suas concentrações comporta esses dois objetivos, pois permite o desenvolvimento desse trabalho a baixo custo e com eficiência técnica.

No caso de obras lineares, a análise de fraturamentos é imprescindível, pois permite o diagnóstico regional das estruturas condizente com a escala destas obras, de forma que, conhecendo-se a direção principal dos fraturamentos de determinada região, é possível garantir melhores escolhas quando da definição de traçados e estratégias para a gestão e manutenção de dutovias.

As obras lineares devem sempre evitar cruzar perpendicularmente ou ortogonalmente as áreas intensamente fraturadas. Devem evitar áreas com alta frequência de lineamento e de cruzamento de lineamentos, pois são sujeitas à percolação de água, sendo, portanto, muito instáveis. Essas informações sobre o meio físico são de interesse nas ações de planejamento ambiental e na concepção de obras de infraestrutura.

AGRADECIMENTOS À Agência Nacional do Petróleo (ANP), à Financiadora de Estudos e Projetos (FINEP) e ao Ministério da Ciência e Tecnologia, por meio do Programa de Recursos Humanos da ANP PRH-5 para o setor de Petróleo e Gás, pelo apoio à pesquisa e concessão da bolsa de Mestrado a Cristiane Alessandra de Moura.

\section{References}

Almeida F. F. M. 1964. Fundamentos Geológicos do Relevo Paulista in Geologia do Estado de São Paulo. Boletim Instituto de Geografia e Geologia, São Paulo, 41:169-263.

Crisóstomo Neto A. P. 2003. Mapeamento Geoambiental por imagem de satélite do Vale do Paraíba. Dissertação de Mestrado em Geociências e Meio Ambiente, Instituto de Geociências e Ciências Exatas, Universidade Estadual Paulista, Rio Claro, 84 p.

Cruz O. A. 1974. Serra do Mar e o Litoral na área de Caraguatatuba-SP: Contribuição a Geomorfologia Litorânea Tropical. Tese de Doutorado em Geografia, FFCLH, Departamento de Geografia, Universidade de São Paulo, São Paulo. 181 p.

Campanha G.A.C., Ens H.H., Ponçano W.L. 1994. Análise morfotectônica do planalto do Juqueriquerê, São Sebastião. Revista Brasileira de Geociências, São Paulo, 24(1):32-42.
Campanha G.A.C. \& Ens H. H. 1996. Estrutura geológica da região da Serra de Juqueriquerê, São Sebastião, Boletim IG-USP. Série Cientifica, 27:41-49.

Franzoni A.M.B. 2000. Avaliação do meio físico para fins de planejamento geoambiental no traçado $e$ manutençãode rede viárias: Ilha de Santa Catarina. Tese de Doutorado, Instituto de Geociências e Ciências Exatas, Universidade Estadual Paulista, Rio Claro, 145 p.

Garda G.M. 1995. Os diques básicos e ultrabásicos da região entre as cidades de São Sebastião e Ubatuba, estado de São Paulo. Tese de Doutorado, Instituto de Geociências, Universidade de São Paulo, São Paulo, 156 p.

Jorge M.C. 2000. Zoneamento Ambiental do município de Ubatuba - SP. Dissertação de Mestrado, Instituto de Geociências e Ciências Exatas, Universidade Estadual Paulista, Rio Claro, 110 p. 
Loczy L. \& Ladeira E. A. 1976. Geologia Estrutural $e$ introdução a geotectônica. São Paulo, Editora Blucher, $528 \mathrm{p}$.

Maffra C.Q.T. 2000. Geologia estrutural do embasamento cristalino na região de São Sebastião, SP: evidencias de um regime transpressivo. Dissertação de Mestrado, Instituto de Geociências, Universidade de São Paulo, São Paulo, 113 p.

Mattos J. T., Jiménez-Rueda J.R., Ohara T., Mendes M.L. de B., Santana M. A. 2002. Critérios para mapeamento de classes a erosão de solos em imagens TM-Landsat. In: Simpósio Latino Americano de Percepción Remota. Cochabamba, Selper, p. 1-9.
O’Leary D.W., Friedman J.D., Pohn H.A. 1976. Lineament, linear, lineation: some proposed new Standards for old terms. Geological Society of America Bulletin, (87):1463-1469.

Peter K.D., Kolm K.E., Downey J.S., Nichols Jr. T.C. 1986. Lineaments: significance, criteria for determination and varied effects on groudwater systems - A case history in the use of remote sensing. Geotechnical applications of remote sensing and remote data transmission. Florida, ASTM (967 STP). p. 46-68.

Manuscrito ID 14799

Recebido em: 19/07/2009 Aprovado em: 23/04/2012 